\title{
Morphology and improved impact strength of cellulose acetate butyrate blended with polyethylene copolymer
}

\author{
A. Podshivalov ${ }^{1 *}$, F. Besson ${ }^{2}$, T. Budtova ${ }^{2}$, S. Bronnikov ${ }^{3}$ \\ ${ }^{1}$ ITMO University, Kronverkskiy Prospekt 49, 197101 Sankt Petersburg, Russian Federation \\ ${ }^{2}$ MINES ParisTech, PSL Research University, CEMEF - Centre de Mise en Forme des Matériaux, UMR CNRS 7635, \\ CS 10207, 06904 Sophia Antipolis, France \\ ${ }^{3}$ Russian Academy of Science, Institute of Macromolecular Compounds, Bolshoi Prospekt 31, 199004 Sankt Petersburg, \\ Russian Federation
}

Received 1 March 2018; accepted in revised form 8 May 2018

\begin{abstract}
Incompatible blends of cellulose acetate butyrate (CAB) and copolymer of ethylene, acrylic ester, and maleic anhydride (PE-Acr-MA) with a component ratio 70/30 vol\% were prepared by melt extrusion at the rates of 150 and $500 \mathrm{rpm}$. The goal was to modify weak impact properties of CAB. We showed that at a speed of $500 \mathrm{rpm}$, both small individual ( $0.9 \mu \mathrm{m}$ in diameter) and large coalesced $(2.3 \mu \mathrm{m}$ in diameter) particles of the PE-Acr-MA phase were formed; the impact strength of the blend increased in 6.5 times as compared with that of pure CAB. However, at a melt mixing rate of $150 \mathrm{rpm}$, the size of the individual PE-Acr-MA particles decreased in 3.8 times, whereas that of the coalesced particles diminished by 6.6 times; the impact strength of the blend increased in about 40 times as compared with that of pure CAB and reached the values around and higher than $70 \mathrm{~kJ} / \mathrm{m}^{2}$. The effect of the screw rotating speed on viscoelastic properties of each component and their viscosity ratio was analyzed and shown to control blend morphology and mechanical properties.
\end{abstract}

Keywords: polymer blends and alloys, cellulose acetate butyrate, polyethylene copolymer, blend morphology, impact properties

\section{Introduction}

By the middle of the last century, cellulose esters were found to be principal polymers for the plastics industry [1]. They were widely used due to their good melt processability and relatively good mechanical properties [2]. However, after the market entry of synthetic petroleum-based polymers, such as polyolefins, the significance of cellulose esters has been dramatically reduced. The reason for this reduction was the high cost of highly purified cellulose in comparison with petroleum-based monomers, as well as easier processability of polyolefins (for example, as opposed to cellulose acetate, they do not need plasticizers) $[1,3,4]$. Moreover, cellulose esters exhibit relatively low impact resistance and elongation at break in comparison with those of petroleum-based polymers.

Within the family of three main cellulose esters, cellulose acetate butyrate (CAB) has the longest substituent which leads to lower glass transition and melting temperatures, and, what is more important, allowing processing the polymer without a plasticizer at several tens of degrees below its degradation temperature. $\mathrm{CAB}$ still finds certain applications as microspheres for drug delivery [5-9], selective membranes [10-12], and orally disintegrating coatings [13]. Additionally, the relevance of $\mathrm{CAB}$ is also growing now due to the human society orientation towards products based on renewable raw materials and biopolymers. 
As most of cellulose esters, CAB is brittle, with low resistance to crack propagation. To overcome this deficiency, blending is one of the solutions frequently used for petrol-based polymers. However, literature on the improvement of mechanical and, in particular, impact properties of $\mathrm{CAB}$ is very scarce. Early patents from Bayer reported on using various copolymers blended with $\mathrm{CAB}$ and sometimes 'bridged' with $\mathrm{CAB}$ through polymerized units of the graft monomers. The examples of copolymers used are ethylene vinyl ester copolymer [14]; graft copolymer of ethylene vinyl ester copolymer having grafted polymerized units of vinyl esters and/or alkyl esters of acrylic and/or methacrylic acid and, optionally, C2-C4-olefins [15]; (meth)acrylic acid C1-C18alkyl esters, vinyl esters and/or alkyl esters of acrylic and/or methacrylic acid and of C2-C4- $\alpha$-olefins [16]. In all cases, an increase in the tensile and notched impact properties were obtained, with the best results of notched impact strength around $12-13 \mathrm{~kJ} / \mathrm{m}^{2}[15$, 16]. Another patent from Eastman also reports on improvement by the mechanical properties of $\mathrm{CAB}$ when blended with a copolymer of methyl acrylatebutyl acrylate [17]. Notched impact strength of some blends increased in slightly less than 3 times as compared to the neat $\mathrm{CAB}$.

Lignin esters were synthesized as biobased filler with the goal to improve $\mathrm{CAB}$ mechanical properties. Their mixtures with $\mathrm{CAB}$ resulted in phase separated blends at all compositions [18]. Lignin esters are oligomers in a glassy state, and being in dispersed phase on the nanoscale level, could potentially reinforce $\mathrm{CAB}$. This is what was observed: at a concentration of lignin butyrate around $20 \mathrm{wt} \%$, the elastic modulus of the blend was increased by $20 \%$. When lignin acetate was used, only one glass transition temperature was recorded, indicating that this lignin ester behaves as a sort of plasticizer [18].

Several publications involving CAB mostly consider it as a minor phase for improving or modifying the mechanical properties of biobased thermoplastics $[19,20]$. For example, poly( $\beta$-hydroxybutyrate) (PHB) was mixed with $\mathrm{CAB}$ with the goal to improve $\mathrm{PHB}$ processability and impact resistance [19]. Various methods confirmed that the components are miscible in the melt state; tensile and impact properties of $\mathrm{CAB} / \mathrm{PHB}$ blends with $\mathrm{CAB}$ in minor phase were improved [19]. A recent study of a blend of $C A B$ with another biodegradable thermoplastic, poly(butylene succinate) (PBS), also showed that PBS and
$\mathrm{CAB}$ are miscible and crystallization rate of PBS was significantly decreased in the presence of amorphous CAB [20]. Young's modulus and tensile strength followed, more or less, the mixing rule while the elongation at break showed a non-monotonous behavior as a function of mixture composition, with a maximum at $40 \mathrm{wt} \% \mathrm{CAB}$ [20]. The addition of CAB to polylactic acid (PLA) strongly decreased PLA crystallization even at low CAB loading, $0.5-1 \mathrm{wt} \%$, keeping crystallization mechanism the same [21]. As far as CAB blends with polyolefins and also some polyesters are concerned, most of them show phase separated morphology [22-28]. The immiscibility of components was used to make blends in which $\mathrm{CAB}$ is in continuous phase and polyolefin or polyester fillers (high density polyethylene (HDPE), isotactic polypropylene (iPP), poly(ethylene terephthalate) (PET), poly(trimethylene terephthalate) (PTT), poly(butylenes terephthalate), and poly(ethylene terephthalate-co-isophthalate)-poly(ethylene glycol)) are in spherical, fibrillar, and lamellar morphology [22-26]. For example, it was shown that the particle size distribution of the fillers had a different width: iPP 2.8-15.0 $\mu \mathrm{m}$, HDPE 2.0-19.0 $\mu \mathrm{m}$, PET $0.9-5.0 \mu \mathrm{m}$, and PTT $0.4-4.0 \mu \mathrm{m}$. A strong influence of iPP content [23] and its molecular weight [24] in the blend with $\mathrm{CAB}$ on the particle size of the dispersed phase was demonstrated. The influence of poly[ethylene-co-(glycidyl methacrylate)] (PE-coGMA) compatibilizer on the size of low density polyethylene (LDPE) dispersed in CAB was also studied [25]. It was found that the introduction of a compatibilizer and an increase in its concentration significantly enhanced the interfacial adhesion and strongly reduced the particle size of the polyolefin. The mean diameter of the LDPE particles at their content of $20 \mathrm{wt} \%$ in the blend was $2.8 \pm 1.4 \mu \mathrm{m}$. However, when $5 \mathrm{wt} \%$ of PE-co-GMA was added, the particle diameter of the LDPE strongly decreased to $0.7 \pm 0.3 \mu \mathrm{m}$. Fourier transform infrared-attenuated total reflectance (FTIR-ATR) spectroscopy showed that epoxy groups of PE-co-GMA strongly interacted with hydroxyl groups of $\mathrm{CAB}$ [25]. Unfortunate$1 y$, the mechanical properties of these blends were not reported.

Summarizing the analysis of available literature data, it becomes clear that blending $\mathrm{CAB}$ with other polymers for improving its impact properties is not well studied. It is known that if willing to improve the impact resistance of a polymer matrix, good dispersion 
of nanoscaled filler of narrow size distribution is very important $[19,29]$. To reach this goal, several parameters, such as the adhesion between the components and their viscosity ratio, which in turn depends on the processing conditions, must be well controlled [22, 24, 29].

In this work, we melt blended $\mathrm{CAB}$ with thermoplastic functionalized polyolefin, such as copolymer of ethylene, acrylic ester, and maleic anhydride (PEAcr-MA), at different mixing rates. The aim of the work was to improve the impact properties of $\mathrm{CAB}$ and establish a correlation with blend morphology. The rheological properties of each component were studied in detail. Viscosity ratio was calculated at different temperatures and mixing rates using modeling of extrusion process.

\section{Materials and methods}

\subsection{Materials}

Cellulose acetate butyrate CAB 531-1 (CAB in the following) manufactured by Eastman (USA) was used as a matrix. $\mathrm{CAB}$ has the degrees of substitution for acetate, butyrate and hydroxyl of $0.2,2.4$, and 0.4, respectively, and a molecular weight of $40000 \mathrm{~g} / \mathrm{mol}$ as given by the manufacturer. As elastomeric filler, we used a thermoplastic functionalized polyolefin Lotader 4700, which is copolymer of ethylene, acrylic ester, and maleic anhydride (PEAcr-MA) with maleic anhydride content $1.3 \mathrm{wt} \%$, kindly provided by Arkema (France). The physical characteristics of the components are presented in Table 1.

\subsection{Differential scanning calorimetry}

Melting and glass transition temperatures of $\mathrm{CAB}$ were determined with differential scanning calorimeter DSC 4000 (Perkin Elmer). Three representative thermograms are given in Figure 1. The first heating scan was performed from -20 to $180^{\circ} \mathrm{C}$ at $10^{\circ} \mathrm{C} / \mathrm{min}$ to erase the thermal history of the polymer. After two hours of temperature stabilization, cooling scan was done from 180 to $-20^{\circ} \mathrm{C}$ at $10^{\circ} \mathrm{C} / \mathrm{min}$. Finally, the second heating scan from -20 to $180^{\circ} \mathrm{C}$ at $10^{\circ} \mathrm{C} / \mathrm{min}$ was performed. Glass transition temperature $T_{\mathrm{g}}$ was

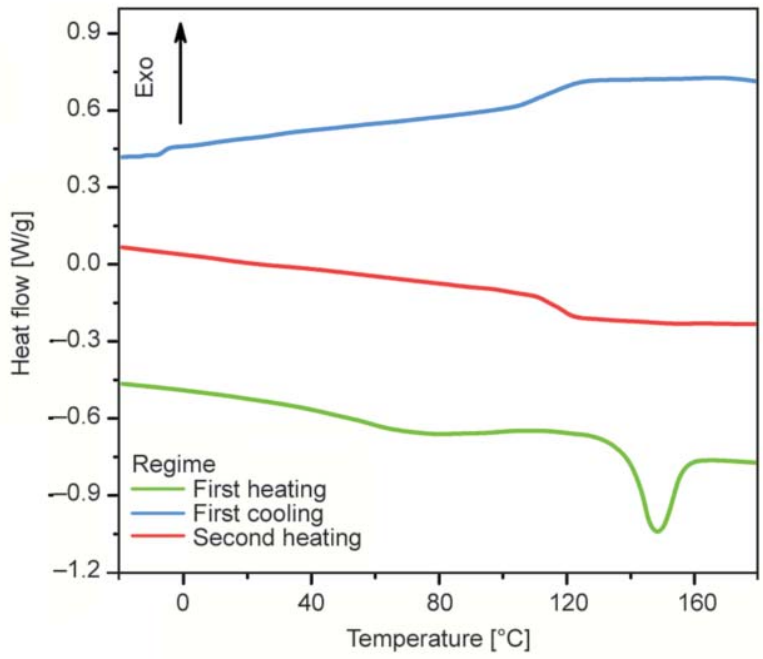

Figure 1. DSC thermograms of $\mathrm{CAB}$, see the text for more details.

recorded at the second heating scan, whereas melting temperature $T_{\mathrm{m}}$ was recorded at the first heating scan. No crystallization/melting was observed during the first cooling and second heating scans whatever the cooling/heating rates (not shown, similar to those in Figure 1), the latter varied from 0.1 to $10^{\circ} \mathrm{C} / \mathrm{min}$. Once melted, $\mathrm{CAB}$ remains amorphous polymer at room temperature. This phenomenon for cellulose esters has already been reported [30, 31].

\subsection{Preparation of blends and samples by melt extrusion and injection}

Before processing, $\mathrm{CAB}$ was vacuum dried at temperature of $70^{\circ} \mathrm{C}$ and pressure of around 100 mbar for several hours. Then a dry mixture of $\mathrm{CAB}$ and PE-Acr-MA 70/30 vol\% was prepared. The compounding was done using a twin-screw co-rotating laboratory-scale extruder from Thermo Fisher, Rheomex PTW 24 OS, with screw diameter $24 \mathrm{~mm}$ and length $960 \mathrm{~mm}$. The screw profile consisting of alternating conveying and left-handed (mixing) zones $(2,3,4$, and 5$)$ is shown in Figure 2. Neat CAB or the $\mathrm{CAB} / \mathrm{PE}-A c r-M A$ mixture was introduced in zone 1. A gravimetric feeder, Brabender Twin Screw Feeder DDW-MD3-DDSR20-10, was used and the flow rate was $2 \mathrm{~kg} / \mathrm{h}$. Two screw speeds were used: 150 and $500 \mathrm{rpm}$. The extrudate was collected, cooled in

Table 1. Physical characteristics of the components as given by the manufacturers (in italic) and measured.

\begin{tabular}{|l|c|c|c|c|}
\hline \multicolumn{1}{|c|}{ Component } & $\begin{array}{c}\text { Density } \\
{\left[\mathbf{g} / \mathbf{c m}^{\mathbf{3}}\right]}\end{array}$ & $\begin{array}{c}\text { Melt-flow index at } \mathbf{1 9 0}{ }^{\circ} \mathbf{C} \text { under pressure } \mathbf{2 . 1 6} \mathbf{~ k g} \\
{\left[\mathbf{g} \cdot \mathbf{1 0} \mathbf{~ m i n}^{-1}\right]}\end{array}$ & $\begin{array}{c}\boldsymbol{T}_{\mathbf{g}} \\
{\left[{ }^{\circ} \mathbf{C}\right]}\end{array}$ & $\begin{array}{c}\boldsymbol{T}_{\mathbf{m}} \\
{\left[{ }^{\circ} \mathbf{C}\right]}\end{array}$ \\
\hline CAB & 1.17 & - & 116 & 148 \\
\hline PE-Acr-MA & 0.94 & 7 & - & 65 \\
\hline
\end{tabular}




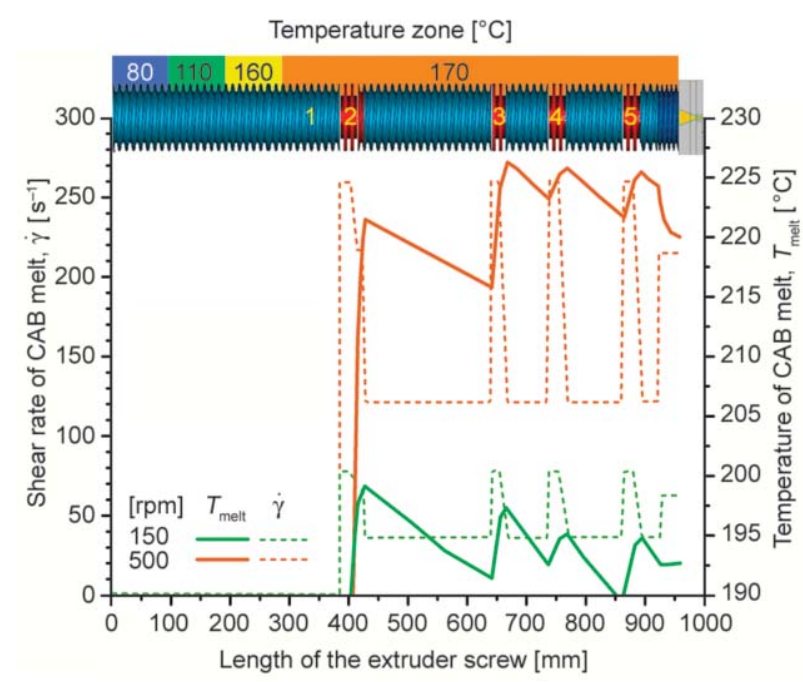

Figure 2. Screw profile of the extruder (the matter is introduced in zone 1 and mixing occurs in zones 2, 3, 4, and 5) and calculated temperature and shear rate evolution along the screw for $\mathrm{CAB}$ at two rotation speeds, 150 and $500 \mathrm{rpm}$.

water, and cut using a Hellweg M 50/80 granulator into pellets of the size around and lower than $5 \mathrm{~mm}$. Neat $\mathrm{CAB}$ underwent the same thermomechanical history as its blend for the adequate comparison.

Bar samples for testing the impact properties of extruded $\mathrm{CAB}$ and $\mathrm{CAB} / \mathrm{PE}-\mathrm{Acr}-\mathrm{MA}$ blends were prepared using EcoPower 55-300 injection molding machine (Wittmann Battenfeld, Austria). The injection speed was $15 \mathrm{~cm}^{3} / \mathrm{s}$ at pressure of 500-600 bar and temperature $180^{\circ} \mathrm{C}$. The samples were rectangular bars of $80 \mathrm{~mm}$ length, $10 \mathrm{~mm}$ width, and $4 \mathrm{~mm}$ thickness according ISO 179-1/1eA norm.

\subsection{Scanning electron microscopy}

For scanning electron microscopy (SEM) observations the injected samples were cryofractured. The fractured surface was metallized by a layer of goldpalladium alloy with thickness $\approx 10 \mathrm{~nm}$ using a metallizer manufactured by JEOL (Japan). The metallized samples were analyzed using a Supra 40 SEM-FEG (Zeiss, Germany) at a vacuum of about $10^{-6}$ bar and at an accelerating voltage of $3.0 \mathrm{kV}$.

\subsection{Statistical analysis of blends morphology}

The analysis of blends morphology was performed using SEM micrographs and statistical approach. The SEM images were segmented with a standard graphical software and planar particle areas $S$ were analyzed statistically using an ImageJ V. $1.51 \mathrm{u}(\mathrm{Na}-$ tional Institutes of Health, Bethesda, MD, USA) software. The number of segmented entities was not less than 100, thus ensuring statistically representative results. For analysis of the blends morphology, the statistical distribution $h(S)$ of the PE-Acr-MA phase were analyzed using Equation (1) derived from the model of reversible aggregation $[32,33]$ :

$h(S)=\sum_{\mathrm{i}=1}^{\mathrm{N}} a_{\mathrm{i}} S_{\mathrm{i}}^{2} \exp \left(-\frac{S_{\mathrm{i}} \Delta u_{0 \mathrm{i}}}{k T}\right)$

where $a$ is a normalizing parameter, $\Delta u_{0 \mathrm{i}}$ is the energy of aggregation in the $i$-th statistical ensemble, $k$ is a Boltzmann constant, $T$ is an absolute temperature, $N$ is a total number of statistical ensembles, and $i$ is the number of the statistical ensemble. Application of this model was successfully confirmed in our previous works where morphology of melt extruded composites based on biopolymers [34] and polyolefins [35-37], as well as the solution casted biocomposites [38], has been analyzed.

\subsection{Melt rheology}

Dynamic oscillatory rheological tests were performed on a strain controlled Advanced Rheometric Expansion System rheometer (TA Instruments). Plateplate geometry was used with plates of $25 \mathrm{~mm}$ diameter and a gap of $1.4 \mathrm{~mm}$. A linear viscoelastic regime was determined at $100 \mathrm{rad} / \mathrm{s}$ and $180^{\circ} \mathrm{C}$ and the strain used in the following was 5\%. Neither degradation nor cross-linking of CAB and PE-AcrMA occurred at the temperatures used in this work as tested by measuring viscosity of the melt as a function of time [28]. Both components did not show any changes within the experimental errors. Frequency sweeps for CAB and PE-Acr-MA were performed from $10^{2}$ to $10^{-2} \mathrm{rad} / \mathrm{s}$.

\subsection{Impact tests}

The impact tests were carried out with notched Charpy method using a Ceast 9050 impact machine (Instron, USA). The impact strength of CAB/PE-AcrMA prepared at $500 \mathrm{rpm}$ was measured at a pendulum velocity of $2.9 \mathrm{~m} / \mathrm{s}$ and at impact energy of $1 \mathrm{~J}$; and of CAB/PE-Acr-MA prepared at $150 \mathrm{rpm}$ at a pendulum velocity of $3.8 \mathrm{~m} / \mathrm{s}$ and impact energy of $7.5 \mathrm{~J}$ as far as these samples were not breaking at lower impact energy. Before testing, samples were stored for three days at $20^{\circ} \mathrm{C}$ and a relative humidity of $50 \%$. At least 10 samples per formulation were measured. 


\section{Results and discussion}

\subsection{Blends morphology}

Figure $3 \mathrm{a}, 3 \mathrm{~b}$ shows the representative SEM images of the CAB/PE-Acr-MA injected samples prepared at two screw speeds, 150 and $500 \mathrm{rpm}$. Similar results (not shown) were obtained for the blend after extrusion. The micrographs demonstrate that the components underwent phase separation with continuous phase of the $\mathrm{CAB}$ matrix and the dispersed phase of the PE-Acr-MA filler, the latter in the form of spherical or elliptical particles. Other researchers have also shown that iPP, PET, PTT, HDPE, PE-co-GMA, LLDPE, and maleated linear low-density polyethylene (M-LLDPE), being blended with CAB, form a dispersed phase as of a spherical or ellipsoidal shape

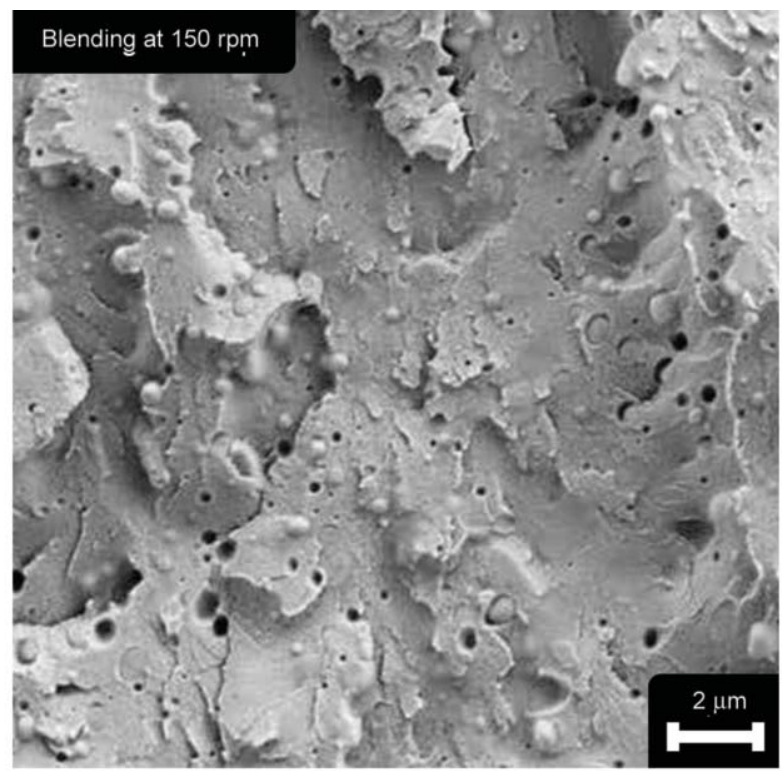

a)

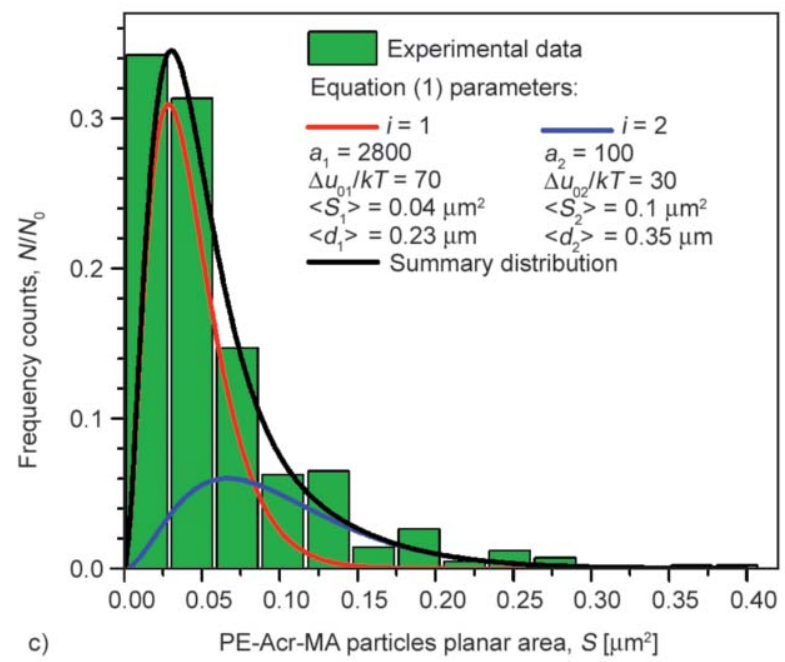

[22-26]. The size and the number of these aggregates depend on the ratio of the components in the mixture $[23,25]$, viscosity ratio of the $\mathrm{CAB}$ to the filler [22, 24], molecular weight of the filler [24], and adhesion of the filler phase to the $\mathrm{CAB}$ phase $[22,26]$. Particularly, PE fillers exhibit poor adhesion to $\mathrm{CAB}$ resulting in formation of big PE particles in the CAB phase $[22,26]$. However, PE-based fillers functionalized with a small amount of MA groups show a strong increase in adhesion and a decrease in interfacial tension with the $\mathrm{CAB}$ leading to a strong reduction in size and dispersion of the filler particles $[25,26]$. In the blend under investigation, interfacial regions show a rather good adhesion between the components. This effect is caused by the

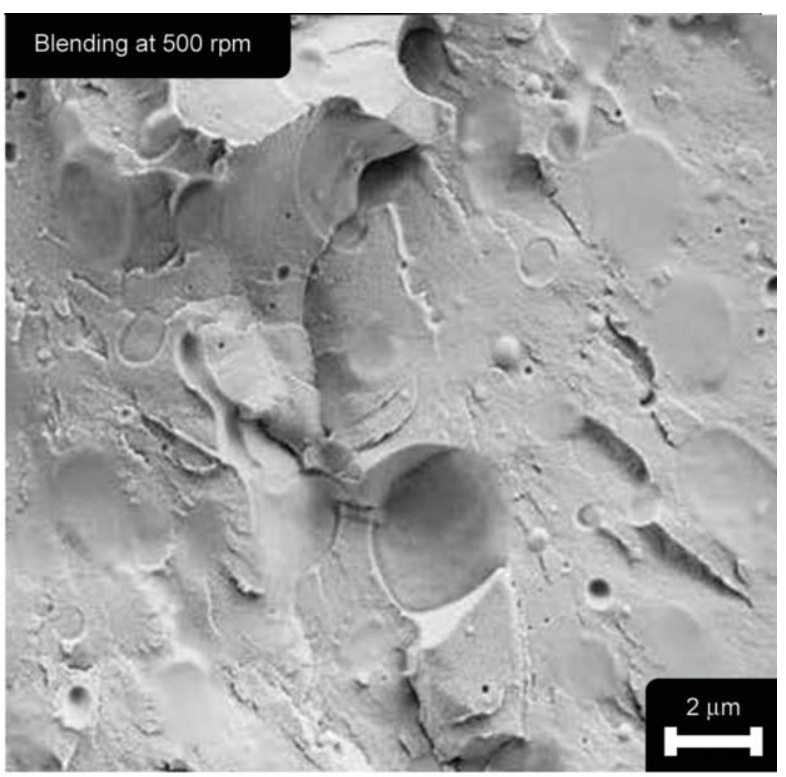

b)

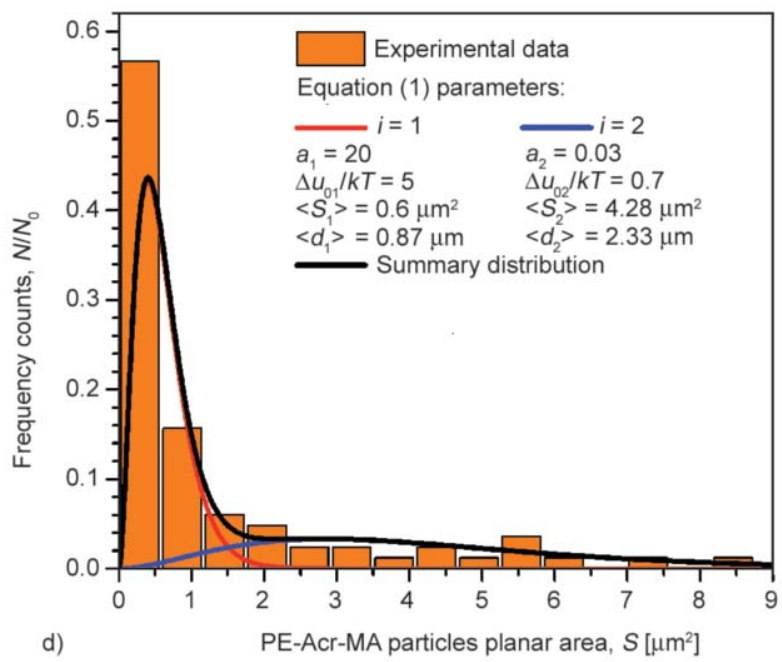

Figure 3. SEM images of CAB/PE-Acr-MA blends prepared at (a) $150 \mathrm{rpm}$ and (b) $500 \mathrm{rpm}$ and the statistical filler particles planar area distributions at (c) $150 \mathrm{rpm}$ and (d) $500 \mathrm{rpm}$ analytically described with the model of reversible aggregation (Equation (1)). 
reaction of polar groups in maleic anhydride in the filler with hydroxyl groups of $\mathrm{CAB}$, which reduces a surface tension at the interface.

Figure $3 \mathrm{c}, 3 \mathrm{~d}$ shows the results of statistical analysis and analytical description of the statistical size distribution of the dispersed phase using Equation (1). It is clear that the model adequately describes the histograms in its bimodal version $(N=2)$. It is known that during mixing of incompatible molten polymers, the continuous phase of minor component breaks and disperses into individual droplets; some of them tend to coalesce due to the increased frequency of collisions between the droplets. Both processes, dispersing and coalescing, occur simultaneously. This explains the presence of two statistical ensembles of the filler particle size: the first one consists of small individual particles, whereas the second one involves the coalesced particles of larger size. The mean particle diameter of the filler, both in individual and coalesced statistical ensembles, at two screw rotation speeds, 150 and $500 \mathrm{rpm}$, are presented in Table 2. It can be seen that the filler particle diameters in both statistical ensembles have the lowest values at $150 \mathrm{rpm}\left(<d_{1}>=0.23 \mu \mathrm{m} ;<d_{2}>=0.35 \mu \mathrm{m}\right)$. Yet, when the speed increases up to $500 \mathrm{rpm}$, the mean particle size, both individual and coalesced, increases in 4-7 times. The results obtained seem to be counter-intuitive since normally increasing mixing rates should produce a higher stress and thus an easier breakage of the minor phase. Here we consider, in the first approximation, only shear forces. We believe that larger droplet size at higher rotating speed is a result of 'unfavorable' evolution of the viscosity ratio $\eta_{\text {filler }} / \eta_{\text {matrix }}$ with increasing rotation speed as will be demonstrated below. Similar phenomenon was reported by Sundararaj and Macosko [39] for polypropylene dispersed in polystyrene. Besides, Wang and Sun [22] demonstrated a strong effect of the viscosity ratio on the droplet size of the filler for the blends of $\mathrm{CAB}$ with polyolefins and polyesters. For example, they have shown that the particle size of the minor phase (iPP) in the $\mathrm{CAB}$ matrix is proportional to the viscosity ratio $\eta_{\text {filler }} / \eta_{\text {matrix }}$ when CAB was meltblended with iPP of different molecular weights [24].

\subsection{Melt viscosity analysis}

In order to determine the viscosity ratio of the filler and the matrix, PE-Acr-MA and CAB, respectively, at 150 and $500 \mathrm{rpm}$, the viscosity of each component at the corresponding temperatures and mixing rates should be known. For this purpose, the evolution of the temperature of the melt $T_{\text {melt }}$ and shear rate $\dot{\gamma}$ in the extruder chamber was simulated using the Ludovic $^{\circledR}$ software developed by CEMEF (MINES ParisTech) and INRA and marketed by the SCC company (Sciences Computers Consultants, Saint Etienne, France) [40]. It is a 1D model based on continuum mechanics, which solves the Stokes equations within the framework of simplified geometry and kinematics, to simulate the whole extrusion process, from the introduction of solid polymer pellets in the hopper to the die exit. This software has been extensively validated by experimental approaches [41] and showed a good fit with more elaborated 3D models [42].

To perform the simulation, it is necessary to know the general rheological properties of the extruded fluid. Because CAB forms the continuous phase, its viscosity was used to estimate $T_{\text {melt }}$ and $\dot{\gamma}$ profiles along extruder screw. The dynamic viscosity of CAB was measured at various temperatures; an example is shown in Figure 4. These data were used to apply time-temperature superposition and build a master plot for the complex viscosity of $\mathrm{CAB}$ at the reference temperature $180^{\circ} \mathrm{C}$ (Figure 5). Solid line corresponds to Carreau-Yasuda model fit (Equation (2)), and the corresponding fitting parameters are given in Table 3:

$\eta^{*}(\omega)=\eta_{0} \cdot a_{\mathrm{T}}\left[1+\left(\lambda \cdot \omega \cdot a_{\mathrm{T}}\right)^{\mathrm{a}}\right]^{\frac{\mathrm{m}-1}{\mathrm{a}}}$

where $\eta_{0}$ is zero-shear rate viscosity, $\omega$ is frequency, $a_{\mathrm{T}}$ is the shift factor, $\lambda$ is the characteristic time, $m$ is the pseudo-plasticity index, and $a$ a fitting parameter. The parameters were calculated with the least squares approximation by minimising the error between the

Table 2. Mean particle diameters, viscosity ratio and impact strength at two screw rotation speeds for the systems studied.

\begin{tabular}{|c|c|c|c|c|c|}
\hline $\begin{array}{l}\text { Composition } \\
\text { [vol\%] }\end{array}$ & $\begin{array}{c}\text { Screw rotation speed } \\
{[\mathrm{rpm}]}\end{array}$ & $\begin{array}{l}<d_{1}> \\
{[\mu \mathrm{m}]}\end{array}$ & $\begin{array}{l}<d_{2}> \\
{[\mu \mathrm{m}]}\end{array}$ & $\eta_{\text {PE-Acr-MA }} / \eta_{C A B}$ & $\begin{array}{c}\text { Impact strength } \\
{\left[\mathrm{kJ} / \mathrm{m}^{2}\right]}\end{array}$ \\
\hline \multirow{2}{*}{$\begin{array}{l}\text { CAB } \\
(100 / 0)\end{array}$} & 150 & - & - & - & $1.8 \pm 0.1$ \\
\hline & 500 & - & - & - & $1.7 \pm 0.1$ \\
\hline \multirow{2}{*}{$\begin{array}{l}\text { CAB/PE-Acr-MA } \\
(70 / 30)\end{array}$} & 150 & 0.23 & 0.35 & 0.6 & $73.6 \pm 17.5$ \\
\hline & 500 & 0.87 & 2.33 & 2.7 & $11.4 \pm 1.5$ \\
\hline
\end{tabular}




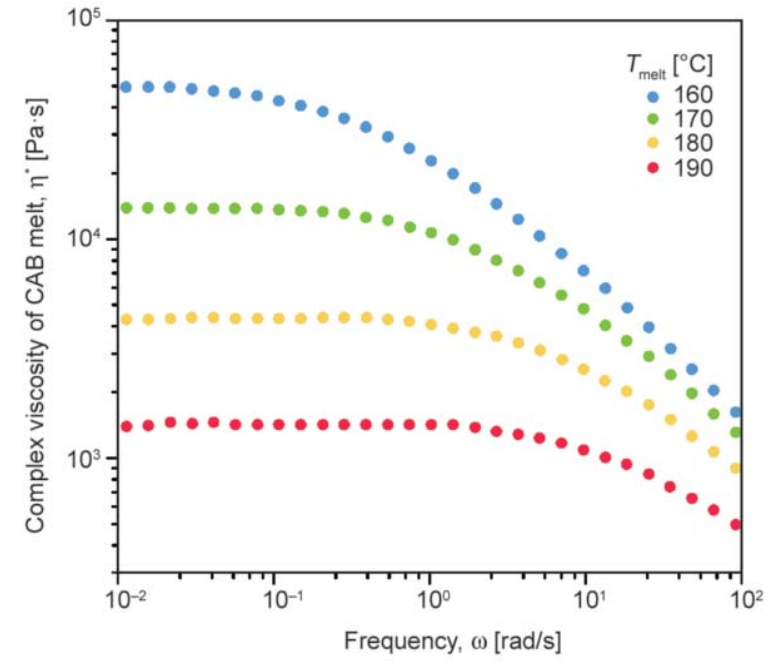

Figure 4. Dynamic viscosity of $\mathrm{CAB}$ as a function of frequency at $160,170,180$, and $190^{\circ} \mathrm{C}$.

model and experimental data. The same procedure was applied to PE-Acr-MA; its' master plot together with Carreau-Yasuda fit is shown in Figure 5. Both melts, $\mathrm{CAB}$ and PE-Acr-MA, are shear thinning fluids.

The evolution of $T_{\text {melt }}$ and $\dot{\gamma}$ along the extruder for 150 and $500 \mathrm{rpm}$ is presented in Figure 2. As expected, higher rotation speed induces higher temperature and shear rate, the former known as self-heating phenomenon. This is due to higher mechanical energy produced in the system [37]. For instance, in the final mixing zone where blend morphology is formed, at $500 \mathrm{rpm} T_{\text {melt }}=224^{\circ} \mathrm{C}$ and $\dot{\gamma}=260 \mathrm{~s}^{-1}$, whereas at $150 \mathrm{rpm} T_{\text {melt }}=194{ }^{\circ} \mathrm{C}$ and $\dot{\gamma}=78 \mathrm{~s}^{-1}$.

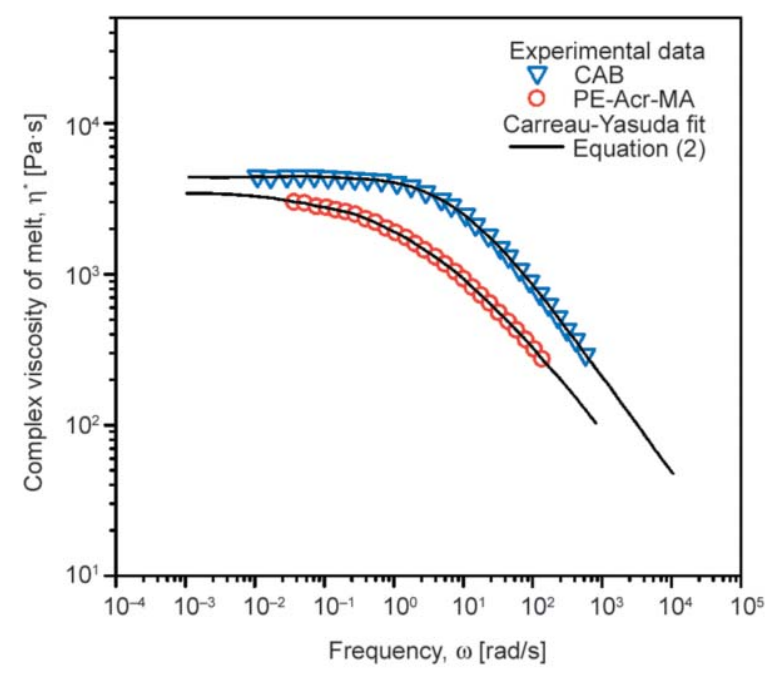

Figure 5. Master plots of the complex viscosity of $\mathrm{CAB}$ and PE-Acr-MA as a function of frequency at a reference temperature of $180^{\circ} \mathrm{C}$. The solid lines correspond to the Carreau-Yasuda model fitting with Equation (2)
Table 3. Carreau-Yasuda model fitting parameters (Equation (2)) for CAB and PE-Acr-MA at reference temperature $180^{\circ} \mathrm{C}$.

\begin{tabular}{|l|c|c|c|c|}
\hline \multicolumn{1}{|c|}{ Polymer } & $\begin{array}{c}\boldsymbol{\eta}_{\mathbf{0}} \\
{[\mathbf{P a} \cdot \mathbf{s}]}\end{array}$ & $\begin{array}{c}\boldsymbol{\lambda} \\
{[\mathbf{s}]}\end{array}$ & $\boldsymbol{m}$ & $\boldsymbol{a}$ \\
\hline $\mathrm{CAB}$ & $4.6 \cdot 10^{3}$ & 0.12 & 0.37 & 0.89 \\
\hline PE-Acr-MA & $3.6 \cdot 10^{3}$ & 0.33 & 0.38 & 0.45 \\
\hline
\end{tabular}

Fitting parameters presented in Table 3 allow determining the viscosity of the components at any temperature and shear rate. Using the obtained above values of temperatures and shear rates in the extruder final mixing zone at 150 and $500 \mathrm{rpm}$, the viscosity ratio $\eta_{\mathrm{PE}-\mathrm{Acr}-\mathrm{MA}} / \eta_{\mathrm{CAB}}$ was found to be 0.6 and 2.7 , respectively (Table 2). It is known that for two immiscible Newtonian fluids the breakage of the minor phase is favorable when the viscosity ratio $\eta_{\text {filler }} / \eta_{\text {matrix }}$ is within $0.1-1$ interval [43]. The same holds true for viscoelastic fluids [44]. We can thus conclude that the viscosity ratio at $500 \mathrm{rpm}$ is not favorable for breaking the droplets as far as the viscosity of the minor phase is higher than that of the continuous phase. Similar effect has earlier been observed for the blends of $\mathrm{CAB}$ with various fillers, including the PE-based fillers $[22,25,27,28]$. The reason is that at $500 \mathrm{rpm}$ melt temperature is $20^{\circ} \mathrm{C}$ higher than at $150 \mathrm{rpm}$ and the $\mathrm{CAB}$ viscosity decreases with increasing temperature in much more significant way than that of PE-Acr-MA. By plotting viscosity vs. inverse temperature (not shown here) according to the Arrhenius approach, we calculated the activation energy of viscous flow for each component. For $\mathrm{CAB}$ it was found to be almost three times higher than that for PE-Acr-MA: $206 \mathrm{~kJ} / \mathrm{mol}$ [28] vs. $73 \mathrm{~kJ} / \mathrm{mol}$, respectively. The analysis of the viscosity-temperature dependence of each component and of their viscosity ratio explains why larger PE-Acr-MA droplets appear in the $\mathrm{CAB} / \mathrm{PE}-\mathrm{Acr}-\mathrm{MA}$ blend at higher rotating speed: at $500 \mathrm{rpm}$, more viscous PE-Acr-MA melt phase cannot easily be dispersed within the lower viscosity $\mathrm{CAB}$ phase.

\subsection{Impact properties}

The result of the impact strength testing of $\mathrm{CAB}$ and $\mathrm{CAB} / \mathrm{PE}-\mathrm{Acr}-\mathrm{MA}$ blends is shown in Table 2. It is clear that the impact strength of the blends considerably exceeds the one of pure $\mathrm{CAB}$. At the extruder screw rotation speed of $150 \mathrm{rpm}$, the extremely high value of impact strength, around and higher than $70 \mathrm{~kJ} / \mathrm{m}^{2}$, is achieved (not all the samples were broken 
at the conditions studied; they rather became ductile, see Figure $6 b$ ). The reason for this behavior is the large amount of small (few hundreds of nanometers) particles of the PE-Acr-MA phase and their good dispersion in the $\mathrm{CAB}$ matrix causing an increased transfer of impact energy to the filler phase. We also believe that this effect implies an enhanced interfacial interaction between the PE-Acr-MA phase and the $\mathrm{CAB}$ phase due to maleic groups binding to hydroxyl groups of the $\mathrm{CAB}$ matrix.

Visual analysis of the samples after impact testing shows that the neat $\mathrm{CAB}$ sample at the fractured area is transparent with a yellow hue (see Figure 6a). After the impact, two smooth and even surfaces are formed, thus demonstrating the material brittleness. The $\mathrm{CAB} /$ PE-Acr-MA blends are slightly translucent; the composite extruded at $500 \mathrm{rpm}$ scatters light more intensively because of near-micron size particles of the dispersed phase (Figure 6c). White area around the impact zone indicates high light scattering due to micro-cavities appearing during matrix plastic deformation, especially visible for the composite extruded at $150 \mathrm{rpm}$ (Figure $6 \mathrm{~b}$ ). The volume of this area relates to a portion of energy absorbed by the material at the impact fracture which is again larger for the composite prepared with lower screw rotation speed.

As mentioned in the Introduction, there are very few reports on the improvement of impact properties of

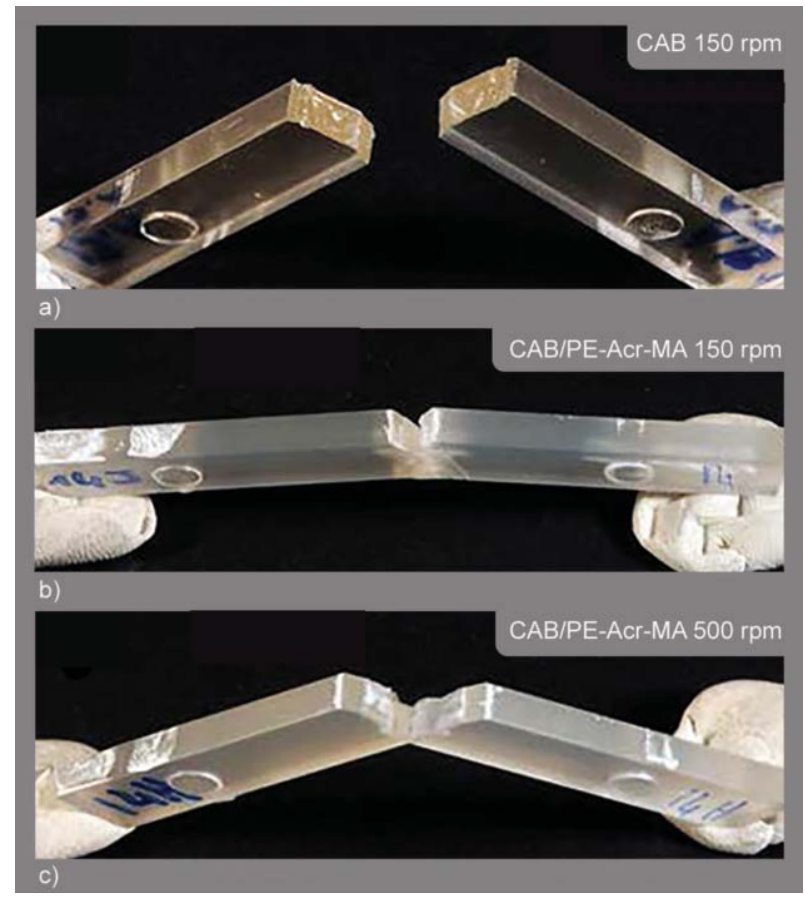

Figure 6. Images of impact zones of (a) neat $\mathrm{CAB}$ and $\mathrm{CAB} /$ PE-Acr-MA blends extruded at (b) $150 \mathrm{rpm}$ and (c) $500 \mathrm{rpm}$.
$\mathrm{CAB}$. When various copolymer esters were used as fillers, the impact strength obtained with notched Charpy tests increased to $12-13 \mathrm{~kJ} / \mathrm{m}^{2}[15,16]$. When copolymer of methyl acrylate-butyl acrylate was blended with $\mathrm{CAB}$, the impact strength was around $5-6 \mathrm{~kJ} / \mathrm{m}^{2}$ [17]. To the best of our knowledge, the impact properties of CAB-containing blends obtained in this work, around $70 \mathrm{~kJ} / \mathrm{m}^{2}$, have never been reported before for this cellulose ester. This impact resistance is similar to the value reported for commercially available high-impact strength polymers, for example, low-density polyethylene $\left(65 \mathrm{~kJ} / \mathrm{m}^{2}\right)$ [45]. The value obtained for CAB/PE-Acr-MA also compares with the best value of impact strength (notched Charpy) obtained for polyamide- 12 reinforced with reactive ethylene/propylene rubber, around $70 \mathrm{~kJ} / \mathrm{m}^{2}$, but is lower than that obtained for polyamide- 12 blended with poly-(styrene)-blockpoly(butadiene)block-poly(methyl methacrylate) triblock terpolymer, $90-120 \mathrm{~kJ} / \mathrm{m}^{2}$ [46].

\section{Conclusions}

Cellulose acetate butyrate/copolymer of ethylene, acrylic ester and maleic anhydride blends with a component ratio of $70 / 30 \mathrm{vol} \%$ were prepared by melt extrusion at screws' rotation speed of 150 and $500 \mathrm{rpm}$. The morphology of the prepared blends showed a heterogeneous structure with a phase separation of the components into a continuous phase of the $\mathrm{CAB}$ matrix and a dispersed phase of the PEAcr-MA particles.

The statistical analysis of the blends morphology showed coalescence of the PE-Acr-MA droplets, leading to formation of larger PE-Acr-MA particles at a screw rotation speed of $500 \mathrm{rpm}$. Interestingly, at a screw rotation speed of $150 \mathrm{rpm}$, the minor phase is intensively dispersing, thus forming the particles of 5-10 times smaller diameter as compared to mixing at $500 \mathrm{rpm}$. The investigation of the components' viscosity ratio showed that at $500 \mathrm{rpm}$ PE-Acr-MA melt is more viscous that $\mathrm{CAB}$ phase leading to larger particle size of the minor phase, from around 0.9 to $2.3 \mu \mathrm{m}$. The opposite case was recorded at $150 \mathrm{rpm}$ : PE-Acr-MA to CAB viscosity ratio is 0.6 resulting in 200-350 nm droplets.

The notched Charpy impact tests showed an increase in the impact strength of both blends as compared to the neat $\mathrm{CAB}$. While at rotation speed $500 \mathrm{rpm}$ the impact resistance increases in 5 times as compared to neat $\mathrm{CAB}$, at $150 \mathrm{rpm}$ the increase is in almost 
40 times, the material becomes ductile. We showed that these effects are controlled by viscosity ratio and the competition of dispersing/coalescing processes of the minor phase droplets in the melt during mixing.

\section{Acknowledgements}

The work was performed in the frame of the Industrial Chair in Bioplastics supported by Arkema, l'Oréal, Nestlé, PSA Peugeot-Citroën and Schneider Electric. We are grateful to Arkema for the help in measuring impact strength.

\section{References}

[1] Edgar K. J., Buchanan C. M., Debenham J. S., Rundquist P. A., Seiler B. D., Shelton M. C., Tindall D.: Advances in cellulose ester performance and application. Progress in Polymer Science, 26, 1605-1688 (2001). https://doi.org/10.1016/S0079-6700(01)00027-2

[2] El Seoud O. A., Heinze T.: Organic esters of cellulose: New perspectives for old polymers. in 'Polysaccharides I. Advances in polymer science' (ed.: Heinze T.) Springer, Berlin, Vol 186, 103-149 (2005). https://doi.org/10.1007/b136818

[3] Thomas S., Visakh P. M., Mathew A. P.: Advances in natural polymers: Composites and nanocomposites. Springer, Berlin (2013). https://doi.org/10.1007/978-3-642-20940-6

[4] Oksman K., Aitomäki Y., Mathew A. P., Siqueira G., Zhou Q., Butylina S., Tanpichai S., Zhou X., Hooshmand S.: Review of the recent developments in cellulose nanocomposite processing. Composites Part A, 83, 2 18 (2016).

https://doi.org/10.1016/j.compositesa.2015.10.041

[5] Phadke K. V., Manjeshwar L. S., Aminabhavi T. M., Sathisha M. P.: Cellulose acetate butyrate bilayer coated microspheres for controlled release of ciprofloxacin. Polymer Bulletin, 75, 1329-1348 (2017). https://doi.org/10.1007/s00289-017-2092-1

[6] Babu V. R., Krishna Rao K. S. V., Lee Y. I.: Preparation and characterization of nifedipine-loaded cellulose acetate butyrate based microspheres and their controlled release behavior. Polymer Bulletin, 65, 157-167 (2010). https://doi.org/10.1007/s00289-009-0238-5

[7] Jelvehgari M., Atapour F., Nokhodchi A.: Micromeritics and release behaviours of cellulose acetate butyrate microspheres containing theophylline prepared by emulsion solvent evaporation and emulsion non-solvent addition method. Archives of Pharmacal Research, 32, 1019-1028 (2009). https://doi.org/10.1007/s12272-009-1707-y

[8] Rokhade A. P., Patil S. A., Belhekar A. A., Halligudi S. B., Aminabhavi T. M.: Preparation and evaluation of cellulose acetate butyrate and poly(ethylene oxide) blend microspheres for gastroretentive floating delivery of repaglinide. Journal of Applied Polymer Science, 105, 2764-2771 (2007).

https://doi.org/10.1002/app.26456
[9] Vaithiyalingam S., Nutan M., Reddy I., Khan M.: Preparation and characterization of a customized cellulose acetate butyrate dispersion for controlled drug delivery. Journal of Pharmaceutical Sciences, 91, 15121522 (2002). https://doi.org/10.1002/jps.10155

[10] Shanbhag A., Barclay B., Koziara J., Shivanand P.: Application of cellulose acetate butyrate-based membrane for osmotic drug delivery. Cellulose, 14, 65-71 (2007). https://doi.org/10.1007/s10570-006-9091-y

[11] Asgarkhani M. A. H., Mousavi S. M., Saljoughi E.: Cellulose acetate butyrate membrane containing $\mathrm{TiO}_{2}$ nanoparticle: Preparation, characterization and permeation study. Korean Journal of Chemical Engineering, 30, 1819-1824 (2013). https://doi.org/10.1007/s11814-013-0122-8

[12] Sobral M. C. C. M., Sobral A. J. F. N., Guthrie J. T., Gil M. H.: Ketotifen controlled release from cellulose acetate propionate and cellulose acetate butyrate membranes. Journal of Materials Science: Materials in Medicine, 19, 677-682 (2008). https://doi.org/10.1007/s10856-007-0168-4

[13] Ali R., Walther M., Bodmeier R.: Cellulose acetate butyrate: Ammonio methacrylate copolymer blends as a novel coating in osmotic tablets. AAPS PharmSciTech, 19, 148-154 (2017). https://doi.org/10.1208/s12249-017-0825-y

[14] Alberts H., Fischer W., Leuschke C., Barti H.: Thermoplastic moulding compositions of cellulose ester graft copolymers or mixtures thereof with cellulose esters. U.S. Patent 4360635 A, USA (1982).

[15] Alberts H., Fischer W., Muller F., Peters H., Leuschke C., Baasch H-P.: Thermoplastic moulding compositions of cellulose esters. U.S. Patent 4357267A, USA (1982).

[16] Alberts H., Fischer W., Leuschke C.: Thermoplastic moulding compositions of cograft polymers of cellulose esters. U.S. Patent 4368292, USA (1983).

[17] Light R. R., Dombroski J. R., Hawkins J. M.: Cellulose ester/copolyacrylate composition. U.S. Patent 4263183A, USA (1981).

[18] Ghosh I., Jain R. K., Glasser W. G.: Multiphase materials with lignin. XV. Blends of cellulose acetate butyrate with lignin esters. Journal of Applied Polymer Science, 74, 448-457 (1999).

https://doi.org/10.1002/(SICI)10974628(19991010)74:2<448::AID-APP28>3.0.CO;2-C

[19] Wang T., Cheng G., Ma S., Cai Z., Zhang L.: Crystallization behavior, mechanical properties, and environmental biodegradability of poly( $\beta$-hydroxybutyrate $) /$ cellulose acetate butyrate blends. Journal of Applied Polymer Science, 89, 2116-2122 (2003). https://doi.org/10.1002/app.12359

[20] Wang X., Huang S., Wang Y., Wei P., Chen Y., Xia Y., Wang Y.: Eco-friendly cellulose acetate butyrate/poly (butylene succinate) blends: Crystallization, miscibility, thermostability, rheological and mechanical properties. Journal of Polymer Research, 24, 16/1-16/9 (2017). https://doi.org/10.1007/s10965-016-1165-4 
[21] Wang Y., Xu Y., He D., Yao W., Liu C., Shen C.: 'Nucleation density reduction' effect of biodegradable cellulose acetate butyrate on the crystallization of poly(lactic acid). Materials Letters, 128, 85-88 (2014). https://doi.org/10.1016/j.matlet.2014.04.078

[22] Wang D., Sun G.: Formation and morphology of cellulose acetate butyrate $(\mathrm{CAB}) /$ polyolefin and $\mathrm{CAB} /$ polyester in situ microfibrillar and lamellar hybrid blends. European Polymer Journal, 43, 3587-3596 (2007). https://doi.org/10.1016/j.eurpolymj.2007.05.018

[23] Wang D., Sun G., Chiou B-S., Hinestroza J. P.: Controllable fabrication and properties of polypropylene nanofibers. Polymer Engineering and Science, 47, 18651872 (2007). https://doi.org/10.1002/pen.20896

[24] Xue C-H., Wang D., Xiang B., Chiou B-S., Sun G.: Morphological development of polypropylene in immiscible blends with cellulose acetate butyrate. Journal of Polymer Research, 18, 1947-1953 (2011). https://doi.org/10.1007/s10965-011-9602-x

[25] Wang D., Sun G., Chiou B-S.: Fabrication of tunable submicro- or nano-structured polyethylene materials from immiscible blends with cellulose acetate butyrate. Macromolecular Materials and Engineering, 293, 657665 (2008).

https://doi.org/10.1002/mame.200800120

[26] Kosaka P. M., Kawano Y., Fantini M. C. A., Petri D. F. S.: Structure and properties of maleated linear low-density polyethylene and cellulose acetate butyrate blends. Macromolecular Materials and Engineering, 291, 531539 (2006).

https://doi.org/10.1002/mame.200500413

[27] Besson F., Budtova T.: Cellulose ester-polyolefine binary blend: Morphological, rheological and mechanical properties. European Polymer Journal, 48, 981-989 (2012).

https://doi.org/10.1016/j.eurpolymj.2012.02.010

[28] Besson F.: Mélanges de polymères thermoplastiques à matrice biosourcée: amélioration de la résistance au choc d'un dérivé cellulosique (in French). Ph.D Thesis, l'École nationale supérieure des mines de Paris, Paris (2013).

[29] Wu S.: Phase structure and adhesion in polymer blends: A criterion for rubber toughening. Polymer, 26, 1855 1863 (1985).

https://doi.org/10.1016/0032-3861(85)90015-1

[30] Boy R. E. Jr., Schulken R. M. Jr., Tamblyn J. W.: Crystallinity in secondary cellulose esters. Journal of applied polymer science, 11, 2453-2465 (1967). https://doi.org/10.1002/app.1967.070111205

[31] Glasser W. G., Samaranayake G., Dumay M., Davé V.: Novel cellulose derivatives. III. Thermal analysis of mixed esters with butyric and hexanoic acid. Journal of Polymer Science Part B: Polymer Physics, 33, 2045 2054 (1995).

https://doi.org/10.1002/polb.1995.090331406
[32] Kilian H. G., Zink B., Metzler R.: Aggregate model of liquids. The Journal of Chemical Physics, 107, 86978705 (1997).

https://doi.org/10.1063/1.475022

[33] Kilian H. G., Bronnikov S., Sukhanova T.: Transformations of the micro-domain structure of polyimide films during thermally induced chemical conversion: Characterization via thermodynamics of irreversible processes. Journal of Physical Chemistry B, 107, 13575-13582 (2003). https://doi.org/10.1021/jp035074m

[34] Gerard T., Budtova T., Podshivalov A., Bronnikov S.: Polylactide/poly(hydroxybutyrate-co-hydroxyvalerate) blends: Morphology and mechanical properties. Express Polymer Letters, 8, 609-617 (2014). https://doi.org/10.3144/expresspolymlett.2014.64

[35] Chen X-H., Yu P., Kostromin S., Bronnikov S.: Minorphase particles evolution in a polyethylene/ethylenepropylene copolymer (80/20) blend across mixing: Breakup and coalescence. Journal of Applied Polymer Science, 130, 3421-3431 (2013). https://doi.org/10.1002/app.39373

[36] Zuev V. V., Steinhoff B., Bronnikov S., Kothe H., Alig I.: Flow-induced size distribution and anisotropy of the minor phase droplets in a polypropylene/poly (ethylene-octene) copolymer blend: Interplay between breakup and coalescence. Polymer, 53, 755-760 (2012).

https://doi.org/10.1016/j.polymer.2011.12.046

[37] Zuev V. V., Bronnikov S. V.: Statistical analysis of morphology of low density polyethylene/polyamide 6 blends with addition of organoclay and maleic anhydridegrafted polystyrene- $b$-poly(ethylene- $c o$-butene- 1$)-b$ polystyrene copolymer as compatibilizers. Journal of Macromolecular Science Part B: Physics, 51, 15581565 (2012).

https://doi.org/10.1080/00222348.2012.656008

[38] Podshivalov A., Zakharova M., Glazacheva E., Uspenskaya M.: Gelatin/potato starch edible biocomposite films: Correlation between morphology and physical properties. Carbohydrate Polymers, 157, 1162-1172 (2017).

https://doi.org/10.1016/j.carbpol.2016.10.079

[39] Sundararaj U., Macosko C.: Drop breakup and coalescence in polymer blends: The effects of concentration and compatibilization. Macromolecules, 28, 2647-2657 (1995).

https://doi.org/10.1021/ma00112a009

[40] Vergnes B., Della Valle G., Delamare L.: A global computer software for polymer flows in corotating twin screw extruders. Polymer Engineering and Science, 38, 1781-1792 (1998). https://doi.org/10.1002/pen.10348

[41] Carneiro O. S., Covas J. A., Vergnes B.: Experimental and theoretical study of twin screw extrusion of polypropylene. Journal of Applied Polymer Science, 78, 1419-1430 (2000).

https://doi.org/10.1002/10974628(20001114)78:7<1419::AID-APP130>3.0.CO;2-B 
[42] Durin A., De Micheli P., Nguyen H-C., David C., Valette R., Vergnes B.: Comparison between 1D and 3D approaches for twin-screw extrusion simulation. International Polymer Processing, 29, 641-648 (2014). https://doi.org/10.3139/217.2951

[43] Utracki L. A., Shi Z. H.: Development of polymer blend morphology during compounding in a twin screw extruder. Part I: Droplet dispersion and coalescence - A review. Polymer Engineering and Science, 32, 1824 1833 (1992).

https://doi.org/10.1002/pen.760322405
[44] Wu S.: Formation of dispersed phase in incompatible polymer blends: Interfacial and rheological effects. Polymer Engineering and Science, 27, 335-343 (1987). https://doi.org/10.1002/pen.760270506

[45] González J., Rosales C., González M., León N., Escalona R., Rojas H.: Rheological and mechanical properties of blends of LDPE with high contents of UHMWPE wastes. Journal of Applied Polymer Science, 134, 44996/1-44996/13 (2017). https://doi.org/10.1002/app.44996

[46] Corté L., Beaume F., Leibler L.: Crystalline organization and toughening: Example of polyamide-12. Polymer, 46, 2748-2757 (2005).

https://doi.org/10.1016/j.polymer.2005.01.040 